\section{ASR \\ Organisational taxonomy and job \\ characteristics on performance: sme case studies}

Edward Wong Sek KHIN, Thanalechumy SEERAMULU, Rusnah MUHAMAD, Mohammad NAZRI and Lau Wee YEAP, Faculty of Business and Accountancy, University of Malaya, Malaysia, E-mail: edwardwong@um.edu.my

\section{Alistract}

This study examines the relationship between the CSR of organizational structure and job characteristics that influence employee job performance in the Malaysian context. Hence, it is important to study and analyze these two factors within the CSR taxonomy describing how these factors significantly influence employee job performance and to make recommendations how performance can be promoted among employees. This paper is based on a quantitative research approach where responses were gathered from the working population within Malaysia SMEs. The results from this study will help to point out the influence of these factors on the employee job performance and provide guidance to an organization for which these aspects should be emphasized in order to increase employees' job performance to align performance with organizational goals. The analysis includes two dimensions of CSR taxonomy of organizational structure namely, centralization and formalization, as well as a set of five dimensions of job characteristics, such as task identity, task significance, skill variety, autonomy and feedback. The results of these findings show that job characteristics such as task significance, autonomy, feedback, and skill variety, positively influence job performance with autonomy having highest predictive power on job performance. The results of these findings reveal that the organizational structure does not contribute to the prediction of job performance even though a significant positive correlation exists between the structure and job performance in the Pearson correlation coefficient test. Therefore, this study will enrich the existing knowledge in the area of human resource management by focusing on job performance management.

Keywords: CSR, organizational structure, job performance and organizational goals.

JEL Classification: M12. M 14

\section{To cite this article:}

Khin, E.W.S., Seeramulu, T., Muhamad, R., Nazri, M. and Yeap,

L.W. (2017), CSR organizational taxonomy and job

characteristics on performance: SME case studies, Audit

Financiar, vol. XV, no. 2(146)/2017, pp. 230-243,

DOI: 10.20869/AUDITF/2017/146/230

To link to this article:

http://dx.doi.org/10.20869/AUDITF/2017/146/230

Received: 12.01.2017

Revised: 15.02 .2017

Accepted: 17.02.2017 


\section{Introduction}

This study is intended for analyzing how the CSR taxonomy of organizational structure and job characteristics influence employee job performance. The results from this study will help to point out the influence of these factors on the employee job performance and provide guidance to an organization for which these aspects should be emphasized in order to increase employees' job performance to align performance with organizational goals. This study will also increase the existing knowledge in the area of human resource management by focusing on job performance management. The recommendations proposed can be used to address any current deterioration of job performance at the workplace or to help prevent such experiences.

CSR taxonomy of employee job performance is defining for the organizational performance and success (Rotundo and Sackett, 2002). Without productive and performing employees, all other efforts to achieve success by the organization can go wrong. High performing employees are not just developing themselves but they contribute significantly to the organization's achievement in the business world. Nevertheless, not all employees perform at the same level and to the expectations of management.

\section{CSR taxonomy of organizational structure}

Different types of CSR taxonomy of organizational structure have different impact on employee performance. Centralization, a major feature of organizational structure, deals mainly with the level of power distributed to the employees to carry out their jobs; there is a lack of job autonomy within centralization, as its major concern is how rigidly an employee is required to follow rules and procedures set up by the organization (Hage and Aiken, 1967). Rigid organizational structure requires employees to adhere to the process and rules in delivering their tasks even if such process is seen as redundant by the employees, as there is a high dependence upon their management or supervisor in respect of decision making. These characteristics of the organization have high impact upon OCB and employee performance. In addition, lack of specific job characteristics such as job autonomy, task significance, and feedback have high impact upon employee performance. Lack of autonomy limits the boundaries of an employee to overperform within the job and in developing positive attitudes such as job satisfaction.

Thus, it is important to develop an in-depth understanding of various factors that influence job performance of human resources and to consider the importance of having high performing employees to keep production competitive in a challenging business environment. In addition, addressing those factors will help the organization to resolve potential job performance problems and also increase employee total performance (Tata and Prasad, 2004).

This study is an extension from previous academic research which attempted to further analyze organization structure and job characteristics and how these influence employee job performance among Malaysian employees working in the private sector. This research aims to answer the following research questions:

a) To what extent does the structure of an organization account for the variance in the employee job performance?

b) Does a less centralized and formalized organization structure increase the worker's job performance?

c) Do task significance, skill variety, and task identity within a job's characteristics, influence employee performance?

d) To what extent do autonomy and feedback of a job's characteristics, influence employee performance?

Below, we review the literature and develop related hypotheses for the variables of interest. The sampling design, selection of measurement scales, and data analysis techniques are then described. This is followed by a presentation and discussion of results, limitations of study, and implications for practitioners and future research.

\section{Literature Review}

The CSR taxonomy of employee job performance is influenced by many factors including the organizational structure as well as the job characteristics related to the particular job itself. It is important for the management to understand to what extent these factors affect the task and contextual performance, so that improvements can be made to promote employee job satisfaction (Viswesvaran and Ones, 2000), as an employee's job performance is essential for an organization's overall effectiveness and achievement of its strategic goals. 
Upon providing a background and definition of key concepts analyzed in this study and based upon a critical literature review concerning organizational structure and job characteristics, the following theoretical model proposes that all five dimensions of job characteristics have an association with employee performance in an organization (Thompson and David,
2005). Similarly, organizational structure or characteristics that are adopted by the organization are also related to the employee job performance and the extent of association depends on the extent those characteristics are being practiced in a particular organization. The following represents the conceptual framework that was developed as part of this study.

\section{Figure 1: Conceptual Framework}

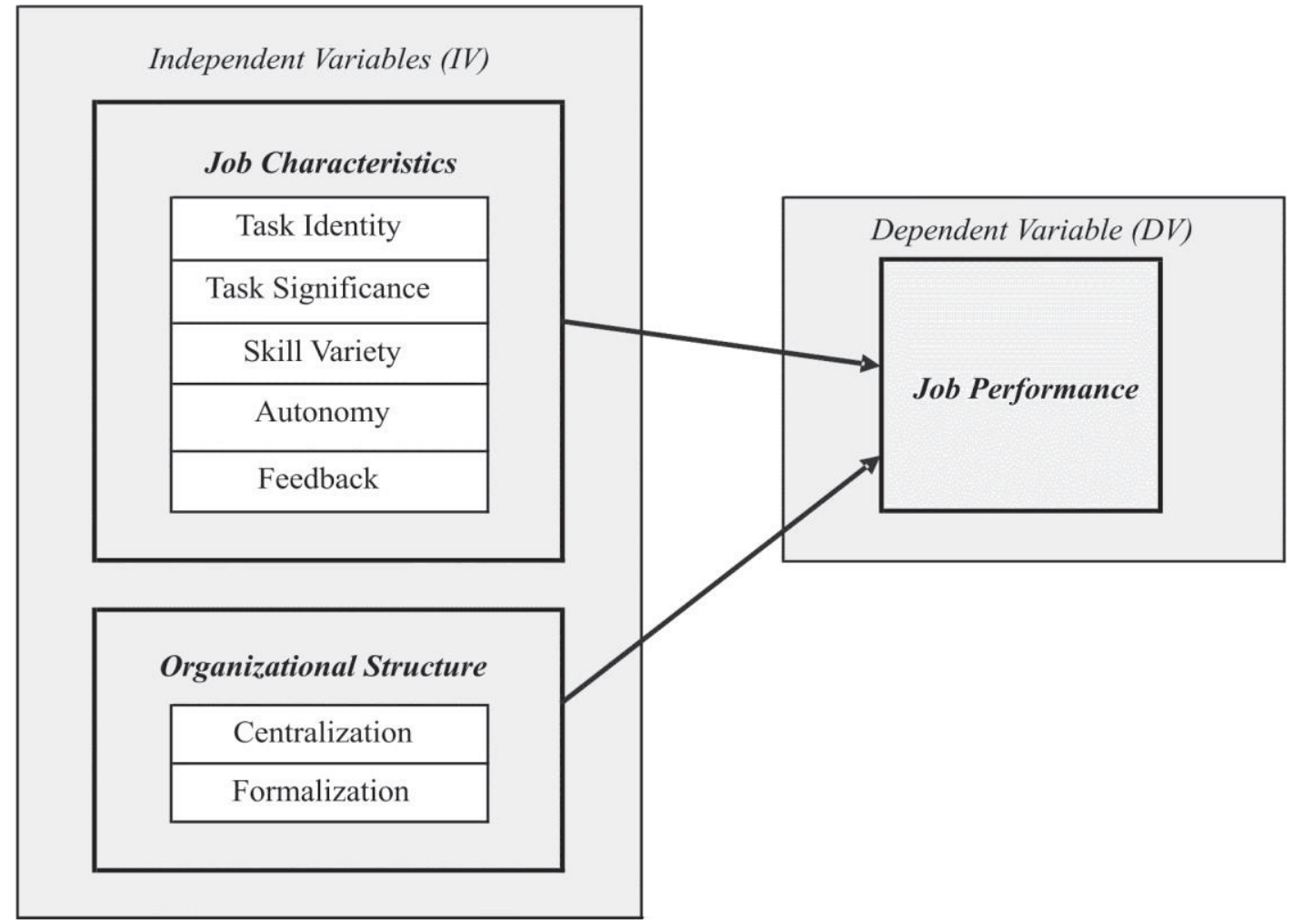

\section{Research method}

\section{Development of Hypotheses}

The following hypotheses were set based on the conceptual framework developed in this study (refer Figure 1).

Hypothesis $1(\mathrm{H} 1)$ : The centralized organization structure is negatively related to the employee job performance and the relationship is significant.

Hypothesis $2(\mathrm{H} 2)$ : The formalized organization structure is negatively related to job performance and the relationship is significant.

Hypothesis $3(\mathrm{H} 3)$ : There is a positive relationship between Task Identity and job performance of the worker and the relationship is significant.

Hypothesis $4(\mathrm{H} 4)$ : The higher the employees feel they perform tasks that have significant impact upon the others, the higher their job performance is.

Hypothesis $5(\mathrm{H} 5)$ : Increasing job autonomy will significantly increase the employee job performance. 
Hypothesis 6 (H6): Job feedback is positively related with job performance and the relationship is significant.

Hypothesis 7 (H7): Skill variety is positively associated with job performance and the relationship is significant.

\section{Data Collection Method}

The study is quantitative and the questionnaires were personally-administered to expedite data collection from respondents to ease clarification when required. The questionnaires were also used because the study is concerned with variables that could not be directly observed. This method is also selected because of the time constraints and urge for speedy responses from the sample for further analysis. The questionnaires are also one of the best ways to collect data from a large sample and in a short time frame (Gay, 1987).

\section{Measurement of Variables}

The variables in the study were measured using a seven (7) point Likert scale as stated below.

$1=$ Strongly Disagree

$2=$ Disagree

$3=$ Slightly Disagree

$4=$ Moderate

$5=$ Slightly Agree

$6=$ Agree

$7=$ Strongly Agree

\section{Survey Instrument}

This study comprises two sets of variables - dependent and independent. Job performance is the dependent variable while job characteristics and organization structure serve as independent variables. The independent variables are further broken down to seven sub-categories consisting of task identity, task significance, skill variety, autonomy and feedback under job characteristics, with centralization and formalization under organizational structure (Morris and Venkatesh, 2010). The questionnaire comprises four sections namely Section A, B, C and D. Section A measures respondent demographics, section $B$ and $C$ measure the independent variables whereas the last section measures the dependent variable. The variables were measured with a series of items that construct and request the respondents to indicate their responses in a 7-point Likert scale illustrated above. Close ended questions were used with options given to state any additional feedback in the last section of the questionnaire.

\section{Job performance (DV)}

Fifteen items were used to measure employee job performance. Two core dimensions of job performance measures were included in this section namely contextual and task performance. Among the items measured for contextual performance are those related to OCB such as tendency to help colleagues, doing more than what is set in the job description, being punctual at work and keeping abreast of organization changes. Under task performance, the concepts measured include the quality of work, completing work on time, collaboration with the team and supervisor and so on. Most importantly, the aim is that to determine whether the job and organization structure characteristics affect both task and contextual performance.

\section{Organizational Structure (IV)}

The CSR taxonomy of organizational structures is divided into two sub-categories to measure centralization and formalization. These sub categories were measured through 7 items each.

\section{Centralization}

This section measures the degree of employee participation in decision making and where the decision making authority lies within an organization (Morgeson and Humphrey, 2006). Questions asked include the organization's hierarchy type, decision making participation, employee inputs to management and so on. The main aim is to evaluate how the hierarchical type influences the performance and how it influence.

\section{Formalization}

This section measures the degree to which the employees have to follow the rules and procedures set out by the organization and whether the employees are reprimanded for infringement of the rules.

\section{Job Characteristics (IV)}

Job characteristic variable are divided into five subcategories to measure task identity, task significance, skill variety, autonomy and feedback 
(Morgeson and Monica, 2005). All sub categories were measured through 7 items each.

\section{Task identity}

Task identity seeks to measure the degree to which employees have the chance to complete the work they start and the significance of their task in delivering the final product and service.

\section{Task Significance}

Task significance measures the level of the employee job significance and impact of their job on the lives of people inside and outside the organization. The questions include data such as whether their job is important to the company survival and how it generally affects the community and so on.

\section{Skill Variety}

Skill variety measures the degree of how the employees exercise different skills in completing their work. The questions include whether their job involve routine, repetitive or non-repetitive tasks.

\section{Autonomy}

Autonomy measures the degree of freedom the employees have in carrying out the work assigned to them (Morgeson and Humphrey, 2006). It measures the freedom in terms of scheduling the work by determining the procedures or methods to carry out their work, the source of the decision making authority for the task, and using own creativity in accomplishing tasks.

\section{Feedback}

Feedback measures the degree of feedback or responses the employee receives from the job itself, from co-workers, supervisors and managers which are the main inputs to enhance the performance of employee.

\section{Study's results}

\section{Descriptive Analysis}

Descriptive analyses were run for the dependent and independent variables in the scope of this study.

Table no. 1. Descriptive Analysis of the Variables

Descriptive Statistics ( $N=83$ )

\begin{tabular}{|l|c|c|c|c|c|c|c|c|c|}
\hline & $\mathbf{N}$ & Min & Max & Mean & Std. Deviation & \multicolumn{2}{|c|}{ Skewness } & \multicolumn{2}{|c|}{ Kurtosis } \\
\cline { 2 - 10 } & Statistic & Statistic & Statistic & Statistic & Statistic & Statistic & Std. Error & Statistic & $\begin{array}{c}\text { Std. } \\
\text { Error }\end{array}$ \\
\hline Centralization & 83 & 2.80 & 6.60 & 4.795 & 0.952 & -0.081 & 0.264 & -1.093 & 0.523 \\
\hline Formalization & 83 & 1.40 & 6.80 & 4.479 & 0.940 & -0.388 & 0.264 & 1.010 & 0.523 \\
\hline Task Identity & 83 & 1.67 & 7.00 & 5.000 & 0.980 & -0.715 & 0.264 & 0.479 & 0.523 \\
\hline Task Significance & 83 & 2.80 & 7.00 & 5.004 & 0.974 & -0.161 & 0.264 & -0.403 & 0.523 \\
\hline Skill Variety & 83 & 3.00 & 7.00 & 5.297 & 0.918 & -0.577 & 0.264 & 0.068 & 0.523 \\
\hline Autonomy & 83 & 2.80 & 7.00 & 4.968 & 0.914 & -0.242 & 0.264 & -0.448 & 0.523 \\
\hline Feedback & 83 & 2.25 & 6.00 & 4.593 & 0.893 & -0.391 & 0.264 & -0.495 & 0.523 \\
\hline Job Performance & 83 & 3.18 & 6.64 & 5.222 & 0.753 & -0.492 & 0.264 & -0.131 & 0.523 \\
\hline
\end{tabular}

\section{Factor Analysis}

Factor analysis is used to reduce large set of components into smaller and more manageable number of components as this study includes 7 dimensions from two independent variables. The objective of factor analysis is also to reject items that do not contribute to the measurement of the concept. The factor analysis output shows the Kaiser-Meyer-Olkin Measure of
Sampling Adequacy $(\mathrm{KMO})$ is above $0.6(\mathrm{KMO}=0.766)$ and the Bartlett's Test of Sphericity is significant at $p<0.05$, indicating that factor analysis is appropriate for these data. The number of components was reduced to 7 which explains $68 \%$ of variance. Varimax rotations were performed to identify the items that makes up the 7 components and the results is presented in Table no. 2 below. 
From the output, task identity is strongly loaded in component 1 whereas task significance, skill variety and autonomy are strongly loaded in component 3, 2 and 5 respectively. Centralization is strongly loaded in component 4. Formalization and feedback are strongly loaded into two components however strong loading for formalization appears in component 6 .

\section{Table no. 2: Factor Analysis}

\section{Rotated Component Matrix}

\begin{tabular}{|c|c|c|c|c|c|c|c|}
\hline \multirow{2}{*}{ Items } & \multicolumn{7}{|c|}{ Component } \\
\hline & 1 & 2 & 3 & 4 & 5 & 6 & 7 \\
\hline JC Task Identity 1 & .653 & & & & & & \\
\hline JC Task Identity 2 & .742 & & & & & & \\
\hline JC Task Identity 3 & .800 & & & & & & \\
\hline JC Task Significance 1 & & & .546 & & .500 & & \\
\hline JC Task Significance 2 & & & .664 & & & & \\
\hline JC Task Significance 3 & .422 & & .526 & & & & \\
\hline JC Task Significance 5 & & & .826 & & & & \\
\hline JC Task Significance 7 & & & .859 & & & & \\
\hline JC Skill Variety 1 & & & & & .797 & & \\
\hline JC Skill Variety 2 & & & & & .676 & & \\
\hline JC Skill Variety 4 & & & .314 & & .700 & & \\
\hline JC Autonomy 1 & & .843 & & & & & \\
\hline JC Autonomy 2 & & .791 & & & & & \\
\hline JC Autonomy 4 & & .705 & & & & & .343 \\
\hline JC Autonomy 6 & & .783 & & & & & \\
\hline JC Autonomy 8 & 650 & .310 & & & & & \\
\hline JC Feedback 1 & .635 & & & & & & \\
\hline JC Feedback 2 & .599 & & & & & .399 & .314 \\
\hline JC Feedback 6 & & & & & & & .832 \\
\hline JC Feedback 7 & 393 & .442 & & & & & .561 \\
\hline OS Formalization 2 & & & & & & .714 & \\
\hline OS Formalization 3 & & .575 & & & & .494 & \\
\hline OS Formalization 5 & .484 & & & & & .464 & \\
\hline OS Formalization 6 & .523 & .436 & & & & & \\
\hline OS Formalization 7 & & & & & & .623 & \\
\hline OS Centralization 1 & & & & .659 & & & -.356 \\
\hline OS Centralization 3 & & .311 & & .730 & & & \\
\hline OS Centralization 4 & & & & .745 & & & \\
\hline OS Centralization 5 & & & & .819 & & & \\
\hline OS Centralization 6 & & & & .574 & .340 & & \\
\hline
\end{tabular}

\section{Reliability Test}

Reliability tests were conducted upon the factor analysis to check the inter-item consistency for each scale as the scale was personally developed by the researcher.
Based on the reliability test output each of the scale returns a Cronbach's Alpha greater than 0.7 as tabulated in Table no. 3 indicating good internal consistency of the scale. 
Table no. 3. Scale Reliability Test

\begin{tabular}{|c|c|}
\hline \multicolumn{2}{|c|}{ Reliability Test } \\
\hline Variable & Cronbach's Alpha \\
\hline Centralization & .778 \\
\hline \begin{tabular}{|l|} 
Formalization \\
\end{tabular} & .760 \\
\hline Task Identity & .817 \\
\hline Task Significance & .844 \\
\hline Skill Variety & .805 \\
\hline Autonomy & .825 \\
\hline Feedback & .736 \\
\hline Job Performance & .824 \\
\hline
\end{tabular}

\section{Normality Test}

Prior to further statistical analysis, a normality test was conducted to check whether the distribution of characteristics of the chosen sample are normally distributed. Skewness and Kurtosis of all the variables are within the acceptable range of $+/-1.5$ which indicates normal distribution of scores. The differences between mean and trimmed mean of the variables do not deviate much and, hence, we concluded that the data are suitable for further statistical analysis.

\section{Independent Samples T-Test}

Independent-Samples T-test is used to compare the mean scores of independent and dependent variables for the categorical variable, gender.
Levene'0073 test findings show a p-value greater than .05 for all variables, indicating that there is no violation to the assumption of equal variance. Further assessment was performed to analyze whether any significant differences exist between the males and females. The score for males $(M=4.74, S D=.97)$ and females $(M=4.82, S D=.95 ; t(81)=-.384$, $p=.702$, two-tailed) for centralization does not show any significance difference. The differences in the means (mean difference $=.082,95 \%$ ) are relatively small. The similar findings were shown for all other variables where there are no statistically significant differences in the mean scores of males and females. The detailed results of independent sample t-test are presented in Table no. 4 below.

\section{Table no. 4. Independent-Samples T-Test}

\begin{tabular}{|c|c|c|c|c|c|c|c|c|c|c|}
\hline & & & & dd & les T & & & & & \\
\hline \multirow{2}{*}{ Variable } & \multirow{2}{*}{ Gender } & \multirow{2}{*}{$\mathbf{N}$} & \multirow{2}{*}{ Mean } & \multirow{2}{*}{$\begin{array}{c}\text { Std. } \\
\text { Deviation }\end{array}$} & \multicolumn{2}{|c|}{$\begin{array}{l}\text { Levene's Test for } \\
\text { Equality of Variances }\end{array}$} & \multicolumn{4}{|c|}{ t-test for Equality of Means } \\
\hline & & & & & $F$ & Sig. & $t$ & df & $\begin{array}{l}\text { Sig. (2- } \\
\text { tailed) }\end{array}$ & $\begin{array}{c}\text { Mean } \\
\text { Difference }\end{array}$ \\
\hline Centralization & $\begin{array}{l}\text { Male } \\
\text { Female }\end{array}$ & $\begin{array}{l}33 \\
50\end{array}$ & $\begin{array}{l}4.7455 \\
4.8280\end{array}$ & $\begin{array}{l}.96601 \\
.95191\end{array}$ & .006 & .938 & -.384 & 81 & .702 & -.08255 \\
\hline Formalization & $\begin{array}{l}\text { Male } \\
\text { Female }\end{array}$ & $\begin{array}{l}33 \\
50\end{array}$ & $\begin{array}{l}4.5091 \\
4.4600\end{array}$ & $\begin{array}{r}1.08753 \\
.84104\end{array}$ & 3.321 & .072 & .231 & 81 & .818 & .04909 \\
\hline Task Identity & $\begin{array}{l}\text { Male } \\
\text { Female }\end{array}$ & $\begin{array}{l}33 \\
50 \\
\end{array}$ & $\begin{array}{l}5.1616 \\
4.8933 \\
\end{array}$ & $\begin{array}{l}.94326 \\
.99986 \\
\end{array}$ & .007 & .934 & 1.223 & 81 & .225 & .26828 \\
\hline Task Significance & $\begin{array}{l}\text { Male } \\
\text { Female }\end{array}$ & $\begin{array}{l}33 \\
50\end{array}$ & $\begin{array}{l}5.1455 \\
4.9120\end{array}$ & $\begin{array}{r}1.03232 \\
.93386\end{array}$ & .488 & .487 & 1.069 & 81 & .288 & .23345 \\
\hline Skill Variety & $\begin{array}{l}\text { Male } \\
\text { Female }\end{array}$ & $\begin{array}{l}33 \\
50\end{array}$ & $\begin{array}{l}5.2525 \\
5.3267\end{array}$ & $\begin{array}{l}.93923 \\
.91222\end{array}$ & .026 & .873 & -.358 & 81 & .721 & -.07414 \\
\hline Autonomy & $\begin{array}{l}\text { Male } \\
\text { Female }\end{array}$ & $\begin{array}{l}33 \\
50\end{array}$ & $\begin{array}{l}5.0364 \\
4.9240\end{array}$ & $\begin{array}{l}.83584 \\
.96881\end{array}$ & 1.319 & .254 & .545 & 81 & .587 & .11236 \\
\hline Feedback & $\begin{array}{l}\text { Male } \\
\text { Female }\end{array}$ & $\begin{array}{l}33 \\
50\end{array}$ & $\begin{array}{l}4.7045 \\
4.5200\end{array}$ & $\begin{array}{l}.90836 \\
.88473\end{array}$ & .021 & .885 & .920 & 81 & .360 & .18455 \\
\hline Job Performance & $\begin{array}{l}\text { Male } \\
\text { Female }\end{array}$ & $\begin{array}{l}33 \\
50\end{array}$ & $\begin{array}{l}5.2658 \\
5.1945\end{array}$ & $\begin{array}{l}.79335 \\
.73305\end{array}$ & .160 & .691 & .420 & 81 & .676 & .07129 \\
\hline
\end{tabular}




\section{Hypothesis Testing}

The hypothesis testing was performed using the Pearson correlation coefficient testing and multiple regression testing. The subsequent section provides the results and interpretation of the hypothesis testing.

\section{Correlation Analysis}

The correlation analysis was performed using Pearson correlation coefficient $(r)$ to investigate the relationship between the variables. Positive correlation between variables indicates that as one variable increases, so does the other variable while negative correlation indicates that increase in value of one variable decreases the value of the other variable (O'Toole and Kenneth, 1999).

There was a moderate positive correlation between centralization and skill variety which is statistically significant $(r=.374, p<.01)$. This shows that the value of one variable will increase with the increase in value of the other variable, however, which variable causing the other variable increase is unknown in correlation coefficient test. Low positive association exists between centralization and job performance $(r=.229, p<.05)$, and the result may be better performance, but the strength is lower.

Statistically significant strong positive correlation was shown between formalization and task identity job characteristics $(r=.611, p<.01)$.

Moderate positive association exists between formalization and task significance and is statistically significant $(r=.435, p<.01)$ whereas only low positive association exists between formalization and skill variety $(r=.314, p<.05)$ and is statistically significant. This reveals that there are possibilities that more formalization in an organization can account for increase in the usage of various skills by the employees on a moderate level.

Autonomy and feedback have strong positive correlation with formalization organization structure with $(r=.506$, $p<.01 ; r=.559, p<.01)$ respectively. Both autonomy and feedback shows statistically significant correlation with formalization. Statistically significant strong positive correlation also exists between formalization and job performance $(r=.540, p<.01)$.

Correlation between task identity and task significance shows strong positive correlation and is statistically significant $(r=.543, p<.01)$. Association between task identity and skill variety also shows moderate association where the result is statistically significant $(r=.472, p<.01)$. Similarly task identity and autonomy share positive moderate correlation which is also statistically significant $(r=.431, p<.01)$.

There is a moderate positive correlation between task identity and feedback $(r=.487, p<.01)$ and is statistically significant. That means more feedback may increase task identity and, on the other hand, higher task identity may result in better job feedback, though, whichever variable has predictive power over the other will be analyzed through multiple regression test. The correlation between task identity and job performance is moderate and positive $(r=.471, p<.01)$.

There is a strong positive association between task significance and skill variety $(r=.600, p<.01)$ and is statistically significant in respect of performing a significant task involving usage of a variety of skillsets by the employee. Task significance shows only moderate positive correlation with autonomy $(r=.395, p<.01)$ and is statistically significant. This shows that increase in autonomy or task significance will increase the value of the other moderately. There is a strong positive association between task significance and job performance $(r=.583, p<.01)$ and shows statistically significant result.

Skill variety shows strong positive correlation with job performance $(r=.556, p<.01)$ and is statistically significant. Higher skill usage will have positive influence on the job performance whereas high job performance value will result in high value of skill variety. Skill variety only shows positive moderate correlation with autonomy $(r=.335, p<.01)$ but statistically significant.

Strong positive correlation exists between job performance and autonomy, showing statistical significance $(r=.604, p<.01)$. Autonomy and feedback only shows moderate positive correlation among each other $(r=.332, p<.01)$ and this correlation is statistically significant. Association between job performance and job feedback is moderate, positive and statistically significant $(r=$ $.441, p<.01)$. Increase in value of feedback on the job will have positive influence on job performance and vice versa but only on a moderate level. The detailed results of the Pearson correlation coefficient among the variables are shown in Table no. 5 . 
Table no. 5. Pearson Correlation Coefficient

\begin{tabular}{|c|c|c|c|c|c|c|c|c|}
\hline Scale & 1 & 2 & 3 & 4 & 5 & 6 & 7 & 8 \\
\hline 1. Centralization & - & & & & & & & \\
\hline 2. Formalization & -0.034 & - & & & & & & \\
\hline 3. Task Identity & 0.073 & $.611^{* *}$ & - & & & & & \\
\hline 4. Task Significance & 0.110 & $.435^{\star *}$ & $.543^{* *}$ & - & & & & \\
\hline 5. Skill Variety & $.374^{* *}$ & $.314^{* *}$ & $.472^{* *}$ & $.600^{* *}$ & - & & & \\
\hline 6. Autonomy & 0.036 & $.506^{\star *}$ & $.431^{* *}$ & $.395^{\star *}$ & $.335^{\star *}$ & - & & \\
\hline 7. Feedback & -0.050 & $.559^{\star *}$ & $.487^{\star *}$ & $.288^{* *}$ & 0.178 & $.332^{* *}$ & - & \\
\hline 8. Job Performance & $.229^{*}$ & $.540^{* *}$ & $.471^{* *}$ & $.583^{* *}$ & $.556^{\star *}$ & $.604^{* *}$ & $.441^{* *}$ & - \\
\hline
\end{tabular}

\section{Testing of Hypothesis Using Correlation Analysis}

Based on the interpretation of the Pearson correlation output, only five hypotheses were supported in terms of the relationship of the job characteristics and the job performance. Hypotheses related to the structure of organization and job performance are not supported in this study. Table no. 6 below sets out the details of the
Pearson's correlation results and summary of the hypothesis testing.

From the analysis it appears that both job characteristics and organization structure has significant positive relationship with employee job performance. However, the result does not support hypotheses 1 and 2 which say the structure is negatively related to job performance.

\section{Table no. 6. Testing of Hypothesis (Correlation Analysis)}

\begin{tabular}{|c|c|c|c|}
\hline Hypothesis & $r$ & Significance & $\begin{array}{l}\text { Supported/ } \\
\text { Not Supported }\end{array}$ \\
\hline $\begin{array}{l}\text { 1. The centralized organization structure is negatively related to the } \\
\text { employee job performance and the relationship is significant. }\end{array}$ & $.229^{*}$ & .037 & Not Supported \\
\hline $\begin{array}{l}\text { 2. The formalized organization structure is negatively related to job } \\
\text { performance and the relationship is significant. }\end{array}$ & $.540^{\star \star}$ & .000 & Not Supported \\
\hline $\begin{array}{l}\text { 3. There is positive relationship between Task Identity and job performance } \\
\text { of the workers and the relationship is significant. }\end{array}$ & $.471^{* *}$ & .000 & Supported \\
\hline $\begin{array}{l}\text { 4. The higher the employees feel they do tasks that have significant impact } \\
\text { on the others, the higher their job performance is. }\end{array}$ & $.583^{\star *}$ & .000 & Supported \\
\hline $\begin{array}{l}\text { 5. Increasing job autonomy will significantly increase the employee job } \\
\text { performance. }\end{array}$ & $.556^{\star *}$ & .000 & Supported \\
\hline $\begin{array}{l}\text { 6. Job feedback is positively related with job performance and the } \\
\text { relationship is significant. }\end{array}$ & $.604^{* *}$ & .000 & Supported \\
\hline $\begin{array}{l}\text { 7. Skill Variety is positively associated with job performance and the } \\
\text { relationship is significant. }\end{array}$ & $.441^{* *}$ & .000 & Supported \\
\hline
\end{tabular}




\section{Multiple Regression}

Multiple regression analysis is performed to further explore the correlation between the variables and the predictive power of the independent variables over the dependent ones represented by job performance. The test is used to identify how well a set of variables predicts a particular outcome. In multiple regression analysis the independent variable that has high predictive power on the dependent variable can be identified and if this variable account for high variance, managers can give more focus to that particular variable in order to improve the performance of the employees. Standard multiple regression test is performed in this study to evaluate the predictive power of the independent variables (centralization, formalization, task identity, task significance, skill variety, autonomy, feedback) in predicting the dependent variable (job performance). The preliminary analysis was conducted to ensure there is no infringement of assumptions of normality, linearity and multicollinearity.

There is a correlation between all the independent variables and the dependent variables. The correlation between the independent variables are less than .7 $(r<.7)$ which assures that there is no infringement of multicollinearity. The tolerance and variance inflation factor (VIF) level of all the variables is also analyzed for the multicollinearity analysis. All variables show tolerance level $>.10$ and VIF of $<10$ which further assures there is no multicollinearity in the data.

The normality is verified using the Normal Probability Plot (P-P) of the Regression Standardized Residual and Scatter-plot. The Normal P-P plot which shows the points which lie in a straight diagonal line assures that there is no major deviation from normality. The scatter plot analysis also shows that the distribution of scores is concentrated in the center. Outliers were also checked using the Residual Statistics table by analyzing the Mahalanobis distance (Mahal. Distance). The distance is compared against the critical chi-square value. As the study has seven independent variables, the critical value suggested by Tabachnick and Fidell (2013) is 24.32 and the regression output result shows 22.29 which suggests that there is no presence of outliers and the preliminary analysis outcome shows there is no violation of the three assumptions.

\section{Multiple Regression Results and Analysis of Variance (ANOVA)}

The multiple correlations $(R)$ between the seven predictors and job performance are strong (.783). The multiple regression model with all seven predictors produced $\mathrm{R}^{2}=.613$. This is $61.3 \%$ and shows that the independent variable affected the dependent variable to an extent of $61.3 \%$. The adjusted r-square $\left(R^{2}\right)$ shows how well the model generalizes and ideally the adjusted $r$-square value should be close to $R^{2}$ and in this case the difference is $(.613-.577=.036$, about $0.036 \%)$. This means that if the model derived from other population instead of the chosen sample, it will account for approximately $0.036 \%$ less variance in outcome. The model causes the $\mathrm{R}^{2}$ changes from zero to .613 , and the result is significant at $\left(F_{2,72}=16.96, p<.05\right)$.

In terms of regression weights, Beta coefficients $(\beta)$, the autonomy of job characteristic has the highest coefficient ( $\beta=.332$ ), followed by task significance $(\beta=.239)$, skill variety at $(\beta=.218)$, feedback at $(\beta=.190)$, formalization at $(\beta=.163)$, centralization at $(\beta=.132)$ and task identity at $(\beta=.107)$. However, only task significance, skill variety, autonomy and feedback show significant contribution in predicting job performance $(p<.05)$. Other variables did not contribute to the model. Hence, from the multiple regression tests, it can be seen that high scores on task significance, skill variety, autonomy and feedback will result in higher job performance among the employees after controlling for other variables in the model. The correlation between the independent and dependent variable are presented in Table no. 7 and Table no. 8 .

\begin{tabular}{|c|c|c|c|c|}
\hline \multicolumn{5}{|c|}{ Model Summaryb } \\
\hline Model & $\mathbf{R}$ & R Square & $\begin{array}{l}\text { Adjusted R } \\
\text { Square }\end{array}$ & Std. Error of the Estimate \\
\hline 1 & $.783^{a}$ & .613 & .577 & .49036 \\
\hline
\end{tabular}


Table no. 8. Independent Variables (F Value)

\begin{tabular}{|c|c|c|c|c|c|c|}
\hline \multicolumn{7}{|c|}{ ANOVA $^{a}$} \\
\hline \multicolumn{2}{|r|}{ Model } & Sum of Squares & df & Mean Square & $F$ & Sig. \\
\hline \multirow[t]{3}{*}{1} & Regression & 28.539 & 7 & 4.077 & 16.956 & $.000^{\mathrm{b}}$ \\
\hline & Residual & 18.034 & 75 & 240 & & \\
\hline & Total & 46.573 & 82 & & & \\
\hline
\end{tabular}

Table no. 9 below shows the coefficients beta $(\beta)$ and their significance for the independent variables.

\section{Table no. 9. Coefficient Beta and Significance of Independent Variables}

\begin{tabular}{|c|c|c|c|c|c|c|}
\hline \multicolumn{7}{|c|}{ Coefficients ${ }^{a}$} \\
\hline & \multirow[t]{2}{*}{ Model } & \multicolumn{2}{|c|}{ Unstandardized Coefficients } & \multirow{2}{*}{$\begin{array}{c}\begin{array}{c}\text { Standardized } \\
\text { Coefficients }\end{array} \\
\text { Beta }\end{array}$} & \multirow[t]{2}{*}{$\mathrm{t}$} & \multirow[t]{2}{*}{ Sig. } \\
\hline & & B & Std. Error & & & \\
\hline \multirow[t]{8}{*}{1} & (Constant) & .580 & .468 & & 1.239 & .219 \\
\hline & Centralization & .104 & .063 & .132 & 1.668 & .100 \\
\hline & Formalization & .131 & .083 & .163 & 1.571 & .120 \\
\hline & Task Identity & -.082 & .080 & -.107 & -1.030 & .306 \\
\hline & Task Significance & .185 & .076 & .239 & 2.420 & .018 \\
\hline & Skill Variety & .179 & .083 & .218 & 2.160 & .034 \\
\hline & Autonomy & .274 & .071 & .332 & 3.841 & .000 \\
\hline & Feedback & .160 & .075 & .190 & 2.124 & .037 \\
\hline
\end{tabular}

\section{Testing of Hypothesis Using Multiple Regression}

Regression analysis outcome reveals that only four hypotheses out of the seven hypotheses set are supported by the regression model.

Hypothesis 1: The centralized organization structure is negatively related to the employee job performance and the relationship is significant, this is not supported by the regression model. The correlation between job performance and centralization is positive in the model and is not significant.

Hypothesis 2: The formalized organization structure is negatively related to job performance and the relationship is significant, this is also not supported by the model. There was positive correlation between formalization and job performance and the results is non-significant.

Hypothesis 3: There is positive relationship between task identity and job performance of the workers and the relationship is significant. This hypothesis is also not supported. There is no negative correlation between the task identity and job performance. Moreover task identity shows nonsignificance in the model.

Hypothesis 4 is supported by the model. There is significant positive correlation between task significance and job performance. Hence, the higher the employees feel they 
do tasks that have significant impact on the others, the higher their job performance is.

Hypothesis 5 is also supported in the regression analysis. Increasing job autonomy will significantly increase the employee job performance and, in fact, autonomy accounts for much higher beta in predicting job performance as compared to the other independent variables.

Hypothesis 6: Job feedback is positively related with job performance and the relationship is significant - this is supported by the model. The positive correlation between feedback and job performance shows that when feedback is given on the job or job output, the job performance will increase.

Hypothesis 7: Skill variety is positively associated with job performance and the relationship is significant - this is also supported by the regression test. The positive correlation between these two variables shows that the higher the usage of different skillset by the workers, the better the output of their job performance. Skill variety significantly contributes to the job performance. The summary of the hypothesis testing is presented in Table no. 10.

Table no. 10. Summary of Hypothesis Testing (Multiple Regressions)

\begin{tabular}{|l|r|r|r|r|}
\hline \multicolumn{1}{|c|}{ Independent Variable } & \multicolumn{1}{|c|}{$\begin{array}{c}\text { Standardized } \\
\text { Coefficients Beta } \\
(\boldsymbol{\beta})\end{array}$} & \multicolumn{1}{|c|}{ Sig. } & Hypothesis & \multicolumn{1}{c|}{$\begin{array}{c}\text { Supported /Not } \\
\text { Supported }\end{array}$} \\
\hline Centralization & .132 & .100 & Hypothesis 1 & Not Supported \\
\hline Formalization & .163 & .120 & Hypothesis 2 & Not Supported \\
\hline Task Identity & -.107 & .306 & Hypothesis 3 & Not Supported \\
\hline Task Significance & .239 & .018 & Hypothesis 4 & Supported \\
\hline Skill Variety & .218 & .034 & Hypothesis 5 & Supported \\
\hline Autonomy & .332 & .000 & Hypothesis 6 & Supported \\
\hline Feedback & .190 & .037 & Hypothesis 7 & \\
\hline a. Dependent Variable: Job Performance & \multicolumn{3}{|l}{} \\
\hline
\end{tabular}

\section{Discussion}

\section{Managerial Implications}

The study proposes a few recommendations to managers from the results of these findings such as to take a more proactive role in designing jobs that give the employees more freedom in carrying out their job responsibilities and making their own decisions that will promote effective performance. As autonomy has significant influence on job performance, providing such freedom to the employees, as they are not bound to strict policies and rules, as long as there is no violation of the code of conduct, it will help the employees to be more independent and accountable for the results of their work. Autonomy also promotes employees to be more creative and innovative in performing the job which ultimately contribute to the organization performance overall (Mathieu and Farr, 1993).
Besides, sufficient consideration should be given to other dimensions of job characteristics such as task significance, skill variety and feedback. Task significance makes significant contribution to performance as in the case when employees feel their jobs contribute to the company, people within the company and even outside of the company such as customers, as it creates a greater sense of achievement which leads and supports them to better performances.

One of the important things that managers need to consider when designing a job is to take into account whether the job will be meaningful to the employee who does the job. Similarly, skill variety is also one of the contributing factors to job performance and therefore, managers should provide opportunities to workers to exercise various skills by combining several tasks. Managers can also combine several tasks that will make up jobs that are more meaningful and give 
them opportunity to exercise different skills in accomplishing their duties. Opportunities that enable employees to exercise more skillsets will also encourage them to continuously learn new skills and plan their career growth. As well, feedback plays an important role. Without feedback, one would not be able to judge whether they are performing adequately or whether the management expects improvement in the performance. Feedback can be in many forms, feedback from the job itself where the job design should be such that the employees know the output requirements of their jobs. The feedback from the management, subordinates and supervisors is extremely important for continuous improvement. Feedback can be in many forms. The common one is via the performance appraisal. However, managers should focus more on continuous feedback on all aspects of the job, which gives them opportunity to benchmark their performance against the feedback given and improve where necessary.

\section{Ronclusion}

In conclusion this research has fulfilled the research objectives, being able to answer the research questions raised in the preliminary stage of the research. This study has identified factors that influence job performance, which include organizational structure consisting in centralization and formalization, and job characteristics. The finding from this research is consistent with the findings from other researches related to job characteristics namely, task significance, skill variety, autonomy and feedback (Jacqueline and Purcell, 2004).

\section{Limitation of the Study}

This study covers employees working in the private sectors across many industries in Malaysia. There is no limitation in this study in terms of type of industries chosen to study the employee job performance. Nevertheless, this study is limited only to private sector employees and employees working in the public sector are excluded from the scope. This study also excludes part time employees and those who are currently not working. The study was conducted in a short period of time and the sample size taken is less than a hundred $(n<100)$, as compared to the studies that were carried out by other researchers. Due to time constraints, the researcher employed convenience sampling which might affect the generalization of the findings. Comprehensive responses using simple random sampling technique would have been collected if time weren't a constraint for this study.

\section{Suggestions for Future Study}

This research is an extension to the previous research performed by other academic and human resource researchers. This study does not provide a new contribution to the area of human resources but attempt to provide better insights on the job performance concept. Secondly, this study uses relatively smaller sample which causes difficulties in respect of adjusting the model with the data gathered. Thirdly our model focuses on responses of working population in Malaysia. Hence, future studies should consider a much bigger population that would be able to provide a more accurate set of findings on the factors that influence job performance such as culture, language and leadership styles. Future research can also focus on other aspects of organizational structure and other factors that may contribute to job performance.

\section{Acknowledgement}

This research is funded by the University of Malaya research grant, Exploratory Research Grant Scheme (ERGS) No. RP030D-15SBS.

\section{REFERENCES}

1. Gay, L.R. (1987), Educational research: Competencies for analysis and application (3rd ed.), Columbus, $\mathrm{OH}$ : Merrill.

2. Hage, J. and Aiken, M. (1967), Relationship of centralization to other structural properties, Administrative Science Quarterly, vol. 12, no. 1, pp. 72-92, DOI: 10.2307/2391213.
3. Jacqueline, A.M., Shapiro, C., Kessler, I. and Purcell, J. (2004), Exploring organizationally directed citizenship behavior: reciprocity or 'tt's my job'? Journal of Management Studies, vol. 41, no. 1, pp. 85-106, DOI: 10.1111/j.1467-6486.2004.00422.x.

4. Mathieu, J.E., Hofmann, D.A. and Farr, J.L. (1993), Job perception - job satisfaction relations: an 
empirical comparison of three competing theories, Organizational Behavior and Human Decision Processes, vol. 56, no. 3, pp. 370-387, DOI: 10.1006/obhd.1993.1060.

5. Morgeson, F.P. and Humphrey, S.E. (2006), The work design questionnaire (WDQ): developing and validating a comprehensive measure for assessing job design and the nature of work, Journal of Applied Psychology, vol. 91, no. 6, pp. 1321-1339, DOl: 10.1037/0021-9010.91.6.1321.

6. Morgeson, F.P., Klinger, K.D. and Monica, A.H. (2005), The importance of job autonomy, cognitive ability, and job-related skill for predicting role breadth and job performance, Journal of Applied Psychology, vol. 90, no. 2, pp. 399-406, DOI: 10.1037/00219010.90.2.399.

7. Morris, M. and Venkatesh, V. (2010), Job characteristics and job satisfaction: understanding the role of enterprise resource planning system implementation, MIS Quarterly, vol. 34, no. 1, pp. 143-161.

8. O'Toole, L.J. Jr. and Kenneth, J.M. (1999), Modelling the impact of public management: implications of structural context, Journal of Public Administration Research and Theory, vol. 9, no. 4, pp. 505-526, DOI: 10.1093/oxfordjournals.jpart.a024421.
9. Rotundo, M. and Sackett, P.R. (2002), The relative importance of task, citizenship, and counter productive performance to global ratings of job performance: a policy-capturing approach, Journal of Applied Psychology, vol. 87, no. 1, pp. 66-80, DOI: 10.1037/0021-9010.87.1.66.

10. Tabachnick, B.G. and Fidell, L.S. (2013), Using multivariate statistics, $\left(6^{\text {th }} \mathrm{ed}\right)$. Boston: Pearson Education.

11. Tata, J. and Prasad, S. (2004), Team selfmanagement, organizational structure, and judgment of team effectiveness, Journal of Managerial Issues, vol. 16, no. 2, pp. 248-265.

12. Thompson, C.A. and David, J.P. (2006), Relationship among organizational family support, job autonomy, perceived eontrol, and employee well-being, Journal of Occupational Health Psychology, vol. 11, no. 1, pp. 100-118, DOI: 10.1037/1076-8998.10.4.100.

13. Viswesvaran, C. and Ones, D.S. (2000). Perspectives on models of job performance. International Journal of Selection and Assessment, vol. 8, no. 4, pp. 216-226, DOl: 10.1111/1468-2389.00151. 